\title{
RESEARCH
}

Open Access

\section{Significance of accurate hilar and intrapulmonary lymph node examination and prognostication in stage IA-IIA non- small cell lung cancer, a retrospective cohort study}

Wenyu Zhai ${ }^{1+}$, Fangfang Duan ${ }^{2 \dagger}$, Yuzhen Zheng ${ }^{3+}$, Qihang Yan ${ }^{1}$, Shuqin Dai ${ }^{4}$, Tao Chen ${ }^{5}$, Jianlong Chen ${ }^{6}$ and Junye Wang ${ }^{1 *}$

\begin{abstract}
Background: The examination of lymph nodes (LNs) plays an important role in the nodal staging of non-small cell lung cancer (NSCLC). For patients without LN metastasis, the main role of thorough $L N$ examination is accurate staging, which weakens the effect of staging migration. To date, the role of hilar and intrapulmonary (N1) station LNs has not been fully appreciated. In this study, we aimed to confirm the significance of N1 LNs in long-term survival for stage IA-IIA NSCLC patients and to find the minimum number of LN to examine.

Methods: The data of patients who underwent radical lobectomy and were confirmed as having non-metastatic LNs from January 2008 to March 2018 were retrospectively screened. Pathology records were reviewed for the number of LNs examined. The Kaplan-Meier method and Cox regression model were used to identify survival and prognostic factors.
\end{abstract}

Results: The median number of resected N1 LNs was 8. The number of patients with 0-2 N1 LNs, 3-5 N1 LNs, 6-8 N1 LNs, 9-11 N1 LNs, and more than $11 \mathrm{~N} 1 \mathrm{LNs}$ examined was 181, 425, 477, 414, and 531, respectively. Sex $(P=$ 0.004), age $(P<0.001)$, tumor size $(P=0.004)$, differentiation degree $(P=0.001)$, and number of $\mathrm{N} 1 \mathrm{LNs}$ examined $(P$ $=0.008)$ were independent prognostic factors of overall survival. Gender $(P=0.006)$, age $(P=0.031)$, tumor size $(P=$ 0.001), differentiation degree $(P=0.001)$, vascular invasion $(P=0.034)$, and number of $\mathrm{N} 1 \mathrm{LNs}$ examined $(P=0.007)$ were independent prognostic factors of disease-free survival. Compared with patients with 0-5 N1 LNs examined, patients with more than $5 \mathrm{~N} 1 \mathrm{LNs}$ examined had better OS $(P=0.015)$ and had better DFS $(P=0.015)$ if only a landmark 5-year follow-up was performed.

(Continued on next page)

\footnotetext{
* Correspondence: wangjy@sysucc.org.cn

${ }^{\dagger}$ Wenyu Zhai, Fangfang Duan and Yuzhen Zheng contributed equally to this work.

'Department of Thoracic Surgery, State Key Laboratory of Oncology in South China, Collaborative Innovation Center for Cancer Medicine, Sun Yat-sen University Cancer Center, Guangzhou, Guangdong, People's Republic of China

Full list of author information is available at the end of the article
}

(c) The Author(s). 2020 Open Access This article is licensed under a Creative Commons Attribution 4.0 International License, which permits use, sharing, adaptation, distribution and reproduction in any medium or format, as long as you give appropriate credit to the original author(s) and the source, provide a link to the Creative Commons licence, and indicate if changes were made. The images or other third party material in this article are included in the article's Creative Commons licence, unless indicated otherwise in a credit line to the material. If material is not included in the article's Creative Commons licence and your intended use is not permitted by statutory regulation or exceeds the permitted use, you will need to obtain permission directly from the copyright holder. To view a copy of this licence, visit http://creativecommons.org/licenses/by/4.0/. The Creative Commons Public Domain Dedication waiver (http://creativecommons.org/publicdomain/zero/1.0/) applies to the data made available in this article, unless otherwise stated in a credit line to the data. 
(Continued from previous page)

Conclusion: Increasing the number of N1 LN examination might improve the long-term survival of T1-2NO NSCLC patients. These data indicate that at least $6 \mathrm{~N} 1$ nodes examined is an essential part in surgical and pathological management but cannot prove this. This finding should be confirmed in a large, prospective randomized clinical study.

Keywords: Non-small cell lung cancer, Lymph node, Prognosis

\section{Background}

Lung cancer remains the most common type of cancer worldwide [1]. For patients with stage IA-IIA non-small cell lung cancer (NSCLC), lobectomy with systemic lymph node (LN) dissection or systematic LN sampling remains the standard therapy $[2,3]$. The 5 -year overall survival (OS) rate of patients with stages IA-IIA is about $60-92 \%$ [4].

Despite radical resection, patients still have a high risk of recurrence. Kelsey et al. reported that the 5-year actuarial risk of disease recurrence was $36 \%$ in patients with stage III NSCLC [5]. Inadequate LN examination may be an important risk factor for recurrence [6]. The examination of LNs plays an important role in accurate node staging, and node-positive patients need adjuvant therapy to reduce their risk of recurrence [7]. For node-positive patients, the removal of metastatic LNs has a therapeutic effect. However, for node-negative patients, the main role of thorough LN examination is accurate staging, which weakens the effect of staging migration. The so-called staging migration refers to the insufficient $\mathrm{LN}$ examination to make $\mathrm{LN}$ positive staging migrate to $\mathrm{LN}$-negative staging. There is still no consensus regarding the optimal number of perioperative LNs to be retrieved for pathological examination. Some studies have shown that a minimum of 10 LNs should be examined to guarantee an accurate $\mathrm{N}$ stage $[8,9]$. Liang et al. mentioned at least 16 LNs should be removed during the surgical procedure [10]. For mediastinal (N2) station LNs, the debate is mainly concentrated on the selection between systemic mediastinal LN dissection and selective mediastinal LN sampling. Several researchers believe that mediastinal LN dissection should be routinely performed during surgeries [7, 11]. In contrary, some studies revealed that selective mediastinal LN sampling had a similar impact on surgical outcomes compared with systemic mediastinal LN dissection for early NSCL C [12-14]. Currently, few studies have focused on the examination of intrapulmonary or hilar (N1) station LNs. To assess the effect of N1 LN examination on the survival of stages IA-IIA NSCLC patients, we retrospectively screened 3014 NSCLC patients from our center and found the minimum number of N1 LNs to examine.

\section{Methods}

\section{Patients}

This study was approved by the Institutional Review Board of Sun Yat-sen University Cancer Center (SYSU
$\mathrm{CC})$. The data of patients who underwent radical surgery at the Thoracic Surgery Department of SYSUCC between January 2008 and March 2018 were reviewed. The inclusion criteria included the following: (1) confirmed pathological diagnosis of NSCLC, (2) pathologically staged as IA-IIA (T1a-2BNOM0), and (3) confirmed negative surgical margin (R0). The exclusion criteria included the following: (1) underwent neoadjuvant therapy, (2) had multiple primary cancers, (3) underwent sublobectomy, and (4) the overall survival (OS) and disease-free survival (DFS) time of less than 1 month. All patients were restaged according to the TNM staging criteria of the 8th National Comprehensive Cancer Network (NCCN) staging system.

\section{Definition and examination of $\mathrm{N} 1$ LNs}

In this study, the dissection of N1 and N2 LN stations was performed by surgeons and reconfirmed by pathologists. N1 LNs specifically refer to LNs in the lobe in which the tumor is located. N2 and hilar LNs were dissected by surgeons during the operation. Interlobar, lobar, segmental, and subsegmental LNs were extracorporeally dissected from lung specimens by surgeons after surgery. The information on the number of LNs examined and other pathological factors were reviewed from pathology reports.

\section{Follow-up}

Follow-ups were performed every 3 months in the first 2 years, every 6 months until 5 years, and once a year thereafter. Surgeons would prescribe chest radiography, ultrasonography, or computed tomography (CT) scans as needed during follow-up. The study endpoints were OS and DFS, which were defined as the time from surgery to death and the time from surgery to first the locoregional or distant recurrence or death, respectively.

\section{Statistical analysis}

All statistical analyses were performed using the SPSS software, version 22.0 (SPSS, Inc., Chicago, IL). Analysis of variance (ANOVA) was performed to compare quantitative data and Pearson's $\chi^{2}$, or Kruskal-Wallis $H$ test was used to compare categorical data between five groups. The OS and DFS were estimated by using the method of Kaplan-Meier method and compared using the log-rank test. Univariate and multivariate Cox proportional hazards regression analyses were used to identify 
prognostic factors for survival. The variables assessed in this study included age, gender, tumor size, smoking history, 8th TNM stage, histology, differentiation degree, visceral pleural invasion, vascular invasion, adjuvant chemotherapy, number of N2 LNs examined, number of N1 LNs examined, and the thoracotomy or video-assisted thoracoscopic surgery (VATS). The number of N2 LNs examined was treated as rank variable categorized into 6 groups, namely, 0 to 2,3 to 5,6 to 8,9 to 11,12 to 15 , and more than 15 . The number of N1 LNs examined was also treated as rank variable categorized into 5 groups, namely, 0 to 2,3 to 5,6 to 8,9 to 11 , and more than 11 . Variables whose $P$ values were $<0.1$ in univariate analyses were included in multivariate analyses. $P$ values $<0.05$ were considered statistically significant, and all hypotheses were two-sided.

\section{Results}

\section{Patient characteristics}

A total of 2028 patients were eligible for analysis (Fig. 1). The patient characteristics are shown in Table 1 . The median age of the 1207 male and 812 female patients investigated was 61 years (range, 20 to 83 years). The main pathological type was adenocarcinoma $(n=1567)$. A total of 266 patients received adjuvant chemotherapy. More than half of the patients $(n=1101)$ underwent minimally invasive VATS, and 927 patients underwent traditional thoracotomy. The median number of N2 LNs examined was 11 (range, 0 to 104). The median number of N1 LNs examined was 8 (range, 0 to 38). The number of patients with $0-2,3-5,6-8,9-11$, and $>11$ examined N1 LNs was 181 (8.9\%), 425 (21.0\%), 477 (23.5\%), 414 (20.4\%), and 531(26.2\%), respectively.

\section{Survival analysis}

The 5-year OS rates of patients with $0-2,3-5,6-8,9-11$, and > 11 examined N1 LNs were 73.8\%, 85.4\%, 89.4\%, $84.0 \%$, and $87.8 \%$, respectively. The 5 -year DFS rates of patients with $0-2,3-5,6-8,9-11$, and $>11$ examined N1 LNs were $60.1 \%, 74.6 \%, 75.1 \%, 76.4 \%$, and $77.3 \%$, respectively. As shown in Fig. 2, patients with $0-2,3-5,6-8,9-11$, and $>11$ examined N1 LNs had clearly different OS (log-rank $p=0.045$, Fig. 2a) and DFS rates $(\log$-rank $p=0.045$, Fig. $2 b)$.

As shown in Table 2, age, gender, tumor size, smoking history, 8th TNM stage, differentiation degree, vascular invasion, and number of N1 LNs examined were statistically significant in univariate analysis of OS, and visceral pleural invasion also had a $p$ value less than 0.1 . In multivariate analysis, advanced age $(P<0.001$; hazard ratio $(\mathrm{HR}) 1.042$; 95\% confidence interval (CI) 1.026-1.059), larger tumor size $(P=0.004$; HR $1.280 ; 95 \%$ CI $1.081-1.516)$, and differentiation degree $(P=0.001$; HR 1.350 ; $95 \%$ CI $1.064-$ 1.714) were negatively correlated with OS. Male sex $(P=$ 0.004; HR 0.535; 95\% CI 0.351-0.814) and number of N1 LNs examined $(P=0.007)$ were positively correlated with OS. Patients with $>11$ N1 LNs $(P<0.001$; HR $0.427 ; 95 \%$ CI $0.266-0.688)$ and $6-8 \mathrm{~N} 1 \mathrm{LNs}(P=0.002$; HR 0.484 ; 95\% CI 0.304-0.770) examined were the two groups with the lowest HR value. All factors except adjuvant chemotherapy, number of N2 LNs examined, and thoracotomy or VATS had a $P$ value less than 0.1 in the univariate analysis of DFS and were enrolled in multivariate analysis (Table 3). In multivariate analysis, advanced age $(P=0.031$; HR $1.012 ; 95 \%$ CI $1.001-1.023)$, larger tumor size $(P=0.001$; HR 1.237 ; 95\% CI 1.094-1.399), differentiation degree $(P=0.001 ; \mathrm{HR} 1.331 ; 95 \% \mathrm{CI}$

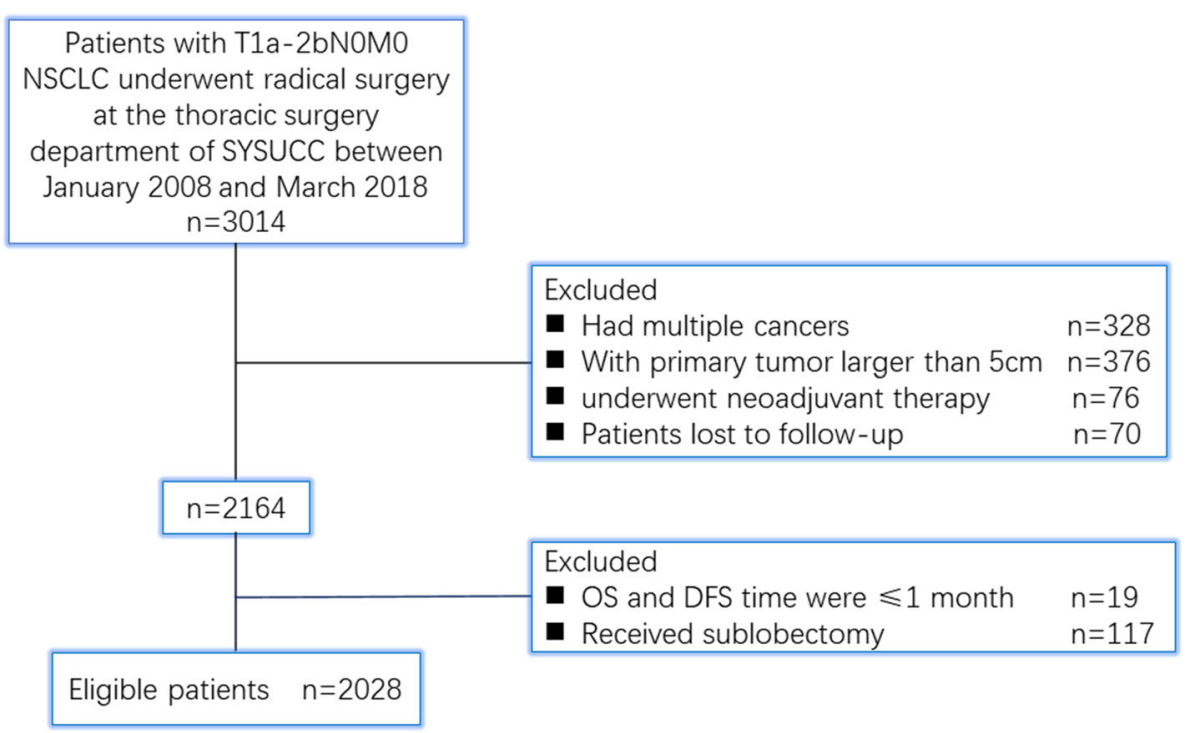

Fig. 1 Flowchart of this study 
Table 1 Patients characteristics

\begin{tabular}{|c|c|c|c|c|c|c|c|}
\hline \multirow[t]{3}{*}{ Characteristics } & \multicolumn{6}{|c|}{ N1 LN subgroups } & \multirow[t]{3}{*}{$P$ value } \\
\hline & $0-2$ & $3-5$ & $6-8$ & $9-11$ & $\geq 12$ & Overall & \\
\hline & $n=181$ & $n=425$ & $n=477$ & $n=414$ & $n=531$ & $n=2028$ & \\
\hline Gender & & & & & & & 0.289 \\
\hline Male & $103(56.9)$ & $246(57.9)$ & $276(57.9)$ & $245(59.2)$ & $337(63.5)$ & $1207(59.4)$ & \\
\hline Female & $78(43.1)$ & $179(42.1)$ & $201(42.1)$ & $169(40.8)$ & $194(36.5)$ & $821(40.5)$ & \\
\hline Age (year) & $60.9 \pm 9.6$ & $60.3 \pm 9.5$ & $59.5 \pm 9.8$ & $59.6 \pm 9.3$ & $59.8 \pm 9.0$ & $59.9 \pm 9.4$ & 0.460 \\
\hline Tumor size (cm) & $2.4 \pm 1.0$ & $2.5 \pm 1.0$ & $2.5 \pm 1.0$ & $2.6 \pm 1.0$ & $2.6 \pm 1.0$ & $2.5 \pm 1.0$ & 0.027 \\
\hline Smoking history & & & & & & & 0.008 \\
\hline No & $115(63.5)$ & $238(56.0)$ & $268(56.2)$ & $224(54.1)$ & $259(48.8)$ & $1104(54.4)$ & \\
\hline Yes or ever & $66(36.5)$ & $187(44.0)$ & 209 (43.8) & $190(45.9)$ & $272(51.2)$ & $924(45.6)$ & \\
\hline 8th TNM stage & & & & & & & 0.537 \\
\hline IA & $86(47.5)$ & $222(52.2)$ & $240(50.3)$ & $194(46.9)$ & $256(48.2)$ & $998(49.2)$ & \\
\hline $\mid \mathrm{B}-\| \mathrm{A}$ & $95(52.5)$ & $203(47.8)$ & $237(49.7)$ & $220(53.1)$ & $275(51.8)$ & $1030(50.8)$ & \\
\hline Histology & & & & & & & 0.582 \\
\hline Adenocarcinoma & $145(80.1)$ & $329(77.4)$ & $365(76.5)$ & $312(75.4)$ & $416(78.3)$ & $1567(77.3)$ & \\
\hline Squamous cell carcinoma & $19(10.5)$ & $66(15.5)$ & $74(15.5)$ & $68(16.4)$ & $83(15.6)$ & $310(15.3)$ & \\
\hline Others & $17(9.4)$ & $30(7.1)$ & $38(8.0)$ & $34(8.2)$ & $32(6.0)$ & $151(7.4)$ & \\
\hline Differentiation degree & & & & & & & 0.054 \\
\hline Well & $26(14.4)$ & $48(11.3)$ & $28(5.9)$ & $38(9.2)$ & $56(10.5)$ & $196(9.7)$ & \\
\hline Moderate & $98(54.4)$ & $224(52.8)$ & $275(57.9)$ & $246(59.6)$ & $264(49.7)$ & $1107(54.7)$ & \\
\hline Poor & $57(31.2)$ & $153(35.9)$ & $174(36.2)$ & $130(31.2)$ & $211(39.7)$ & 725 (35.6) & \\
\hline Visceral pleural invasion & & & & & & & 0.605 \\
\hline Negative & $119(65.7)$ & $306(72.0)$ & $329(69.0)$ & $288(69.6)$ & $375(70.6)$ & $1417(69.9)$ & \\
\hline Positive & $62(34.3)$ & $119(28.0)$ & $148(31.0)$ & $126(30.4)$ & $156(29.4)$ & $611(30.1)$ & \\
\hline Vascular invasion & & & & & & & 0.843 \\
\hline Negative & $168(92.8)$ & $399(93.9)$ & $442(92.7)$ & $391(94.4)$ & $496(93.4)$ & 1896 (93.5) & \\
\hline Positive & $13(7.2)$ & $26(6.1)$ & $35(7.3)$ & $23(5.6)$ & $35(6.6)$ & $132(6.5)$ & \\
\hline Number of N2 LNs examined & & & & & & & $<0.001$ \\
\hline $0-2$ & $24(13.3)$ & $24(5.6)$ & $29(6.1)$ & $13(3.1)$ & $21(4.0)$ & $111(5.5)$ & \\
\hline $3-5$ & $29(16.0)$ & $62(14.6)$ & $66(13.8)$ & $54(13.0)$ & $53(10.0)$ & $264(13.0)$ & \\
\hline $6-8$ & $40(22.1)$ & 79 (18.6) & $83(17.4)$ & 68 (16.4) & $78(14.7)$ & $348(17.2)$ & \\
\hline $9-11$ & $25(13.8)$ & $56(13.2)$ & $83(17.4)$ & $60(14.5)$ & $76(14.3)$ & $300(14.8)$ & \\
\hline $12-14$ & $20(11.0)$ & $72(16.9)$ & $69(14.5)$ & $65(15.7)$ & $72(13.6)$ & $298(14.7)$ & \\
\hline$\geq 15$ & $43(23.8)$ & $132(31.1)$ & $147(30.8)$ & $154(37.2)$ & $231(43.5)$ & 707 (34.9) & \\
\hline Adjuvant chemotherapy & & & & & & & 0.582 \\
\hline No & $160(88.4)$ & $363(85.4)$ & $413(86.6)$ & $368(88.9)$ & $458(48.2)$ & $1762(86.9)$ & \\
\hline Yes or ever & $21(11.6)$ & $62(14.6)$ & $64(13.4)$ & $46(11.1)$ & $73(13.7)$ & $266(13.1)$ & \\
\hline Thoracotomy or VATS & & & & & & & 0.176 \\
\hline Thoracotomy & $68(37.6)$ & $193(45.4)$ & $230(48.2)$ & $194(46.9)$ & $242(45.6)$ & $927(45.7)$ & \\
\hline VATS & $113(62.4)$ & $232(54.6)$ & $247(51.8)$ & $220(53.1)$ & $289(54.4)$ & $1101(54.3)$ & \\
\hline
\end{tabular}

1.119-1.584), and vascular invasion $(P=0.034$; HR 1.506; $95 \%$ CI $1.031-2.200)$ were negatively correlated with DFS. Male sex $(P=0.006$; HR $0.663 ; 95 \%$ CI $0.495-0.888$ ) and the number of $\mathrm{N} 1 \mathrm{LNs}$ examined were positively correlated with DFS. Patients with $>11 \mathrm{~N} 1$ LNs $(P=0.001$; HR 0.542 ; $95 \%$ CI $0.384-0.766)$ and $9-11$ N1 LNs $(P=0.002$; HR 0.570; 95\% CI 0.399-0.813) examined were the two groups with the lowest HR value. 

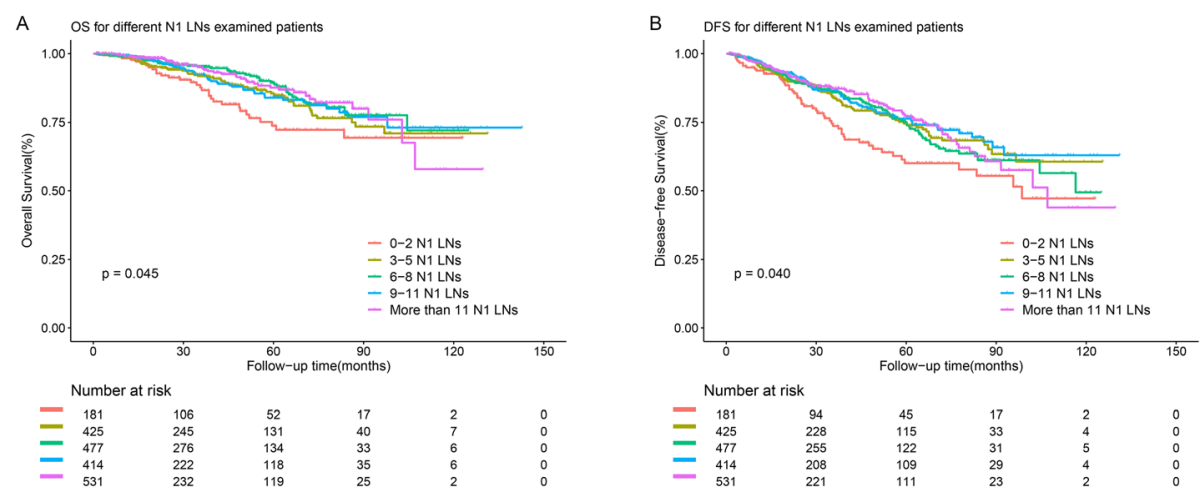

Fig. 2 a OS for patients with different N1 LNs examined patients. b DFS for patients with different N1 LNs examined patients

Then, we compared prognosis between patients with $0-5 \mathrm{~N} 1 \mathrm{LNs}$ examined and patients with more than 5 N1 LNs examined. As shown in Fig. 3, the 5-year OS rates of patients with more than $5 \mathrm{~N} 1 \mathrm{LNs}$ examined was significantly higher than the 5-year OS rates of patients with $0-5 \mathrm{~N} 1 \mathrm{LNs}$ examined (87.1\% versus $81.9 \%$, $\log$-rank $P=0.015$, Fig. 3a), while the 5 -year DFS rates of patients with more than $5 \mathrm{~N} 1 \mathrm{LNs}$ examined was not apparently higher than the 5-year DFS rates of patients with $0-5 \mathrm{~N} 1 \mathrm{LNs}$ examined $(76.2 \%$ versus $70.2 \%$, logrank $p=0.106$, Fig. $3 \mathrm{~b}$ ). And examining more than $5 \mathrm{~N} 1$ LNs is a positive prognostic factor in multivariate analyses of OS $(P=0.013$; HR 0.704 ; 95\% CI $0.533-0.929)$ and DFS $(P=0.035 ;$ HR $0.800 ; 95 \%$ CI $0.650-0.984)$. If only a landmark 5 -year follow-up was performed, patients with more than $5 \mathrm{~N} 1 \mathrm{LNs}$ examined had significantly better DFS ( $P=0.015$, Fig. $3 c)$.

\section{Discussion}

In the treatment of NSCLC patients, accurate node staging is important for predicting prognosis and selecting an appropriate treatment strategy. Clinical $\mathrm{N}$ staging based solely on CT and positron emission tomography (PET) is not accurate enough for early NSCLC [15]. Thorough postoperative pathological $\mathrm{N}$ examination is optimal for $\mathrm{N}$ staging. The number of LNs examined is an intuitive indicator of examination thoroughness. In this study, we found that the number of N1 LNs examined was an independent prognostic factor of OS and DFS for stage IA-IIA patients.

There are some potential explanations for the survival advantage brought by the larger number of N1 LNs examined. An increasing number of N1 LNs examined would lead to a greater probability of discovering metastasized LNs in the hilum and lung, leading to stage migration, which is considered to be the main factor for the improvement of OS and DFS in patients with a large number of N1 LNs examined. Inadequate LN examination may result in some metastatic LNs not being detected, and patients would be wrongly staged as IA or IB when they should be staged as IIB and receive adjuvant therapy. The resection of micrometastases and the effect of the immunologic microenvironment may also be related to the survival advantage brought by the larger number of N1 LNs examined [16-19]. In this study, patients who underwent sublobectomy were excluded which means all intrapulmonary lymph nodes are removed along with the lobes. The resection of micrometastases did not have a significant impact on the survival advantage brought by the larger number of N1 LNs examined.

Several researchers have emphasized that a larger number of LNs examined could increase the accuracy of $\mathrm{N}$ staging and enhance prognosis. Samayoa et al. retrospectively analyzed 98,970 patients from The National Cancer Data Base (NCDB) and found that the amounts of LNs examination apparently affect the long-term survival, and at least 10 LNs should be examined in surgical management [17]. Ou and Zell retrospectively investigated the data of 2545 patients and confirmed that the number of LN examination was the favorable prognostic factor for stage IA patients and suggested that the removal of 11-15 LNs could improve the patients prognosis [20]. However, the above two studies did not separately analyze the effects of N1 and N2 LNs on survival.

In our pilot study, the number of LNs examined was identified as an independent prognostic factor for OS $(P$ $=0.005)$. In this study, the survival advantage from the increase in the number of LNs examined should be attributed to the increase in the number of N1 LNs examined, which might be associated with the following reason. The patients in this study underwent a highquality mediastinal LN dissection. The number of patients with at least 1,2 , and $3 \mathrm{~N} 2$ stations dissected was 1992 (98.2\%), 1864 (91.9\%), and 1457 (71.8\%), respectively, and the median number of N2 LNs examined was 11 in this study. The median number of $\mathrm{N} 2$ LNs examined was 12 in the American College of 
Table 2 Univariate and multivariate analysis of OS

\begin{tabular}{|c|c|c|c|c|}
\hline \multirow[t]{2}{*}{ Factors } & \multicolumn{2}{|l|}{ Univariate analysis } & \multicolumn{2}{|c|}{ Multivariate Analysis } \\
\hline & $\mathrm{HR}(95 \% \mathrm{Cl})$ & $P$ value & $\mathrm{HR}(95 \% \mathrm{Cl})$ & $P$ value \\
\hline Gender & $0.393(0.283-0.546)$ & $<0.001$ & $0.538(0.352-0.821)$ & 0.004 \\
\hline Age (year) & $1.049(1.033-1.066)$ & $<0.001$ & $1.042(1.025-1.058)$ & $<0.001$ \\
\hline Tumor size (cm) & $1.461(1.288-1.657)$ & $<0.001$ & $1.274(1.075-1.510)$ & 0.005 \\
\hline Smoking history & $2.067(1.558-2.742)$ & $<0.001$ & $1.107(0.764-1.603)$ & 0.592 \\
\hline 8th TNM stage & $1.818(1.364-2.425)$ & $<0.001$ & $1.196(0.762-1.878)$ & 0.437 \\
\hline Visceral pleural invasion & $1.281(0.973-1.687)$ & 0.077 & $1.180(0.818-1.702)$ & 0.377 \\
\hline \multicolumn{5}{|l|}{ Histology } \\
\hline Squamous cell carcinoma & Ref & & Ref & \\
\hline Adenocarcinoma & $0.629(0.459-0.864)$ & 0.004 & $1.061(0.745-1.513)$ & 0.742 \\
\hline Others & $0,946(0.581-1.1542)$ & 0.825 & $1.225(0.734-2.043)$ & 0.437 \\
\hline Differentiation degree & $1.683(1.341-2.112)$ & $<0.001$ & $1.349(1.063-1.711)$ & 0.014 \\
\hline Vascular invasion & 1.899 (1.119-3.222) & 0.017 & $1.398(0.805-2.429)$ & 0.235 \\
\hline \multicolumn{5}{|l|}{ Number of N2 LNs examined } \\
\hline $0-2$ & Ref & & & \\
\hline $3-5$ & $0.427(0.244-0.783)$ & 0.006 & $0.565(0.302-1.056)$ & 0.073 \\
\hline $6-8$ & $0.629(0.368-1.073)$ & 0.089 & $0.745(0.429-1.294)$ & 0.296 \\
\hline $9-11$ & $0.516(0.292-0.913)$ & 0.023 & $0.663(0.367-1.198)$ & 0.174 \\
\hline $12-14$ & $0.648(0.372-1.129)$ & 0.126 & $0.887(0.497-1.583)$ & 0.686 \\
\hline$>14$ & $0.563(0.342-0.929)$ & 0.024 & $0.654(0.388-1.102)$ & 0.111 \\
\hline Adjuvant chemotherapy & $0.925(0.625-1.369)$ & 0.695 & & \\
\hline Thoracotomy or VATS & $0.864(0.655-1.141)$ & 0.304 & & \\
\hline \multicolumn{5}{|l|}{ Number of N1 LNs examined } \\
\hline $0-2$ & Ref & & Ref & \\
\hline $3-5$ & $0.702(0.451-1.091)$ & 0.116 & $0.631(0.403-0.987)$ & 0.044 \\
\hline $6-8$ & $0.533(0.336-0.844)$ & 0.007 & $0.489(0.307-0.779)$ & 0.003 \\
\hline $9-11$ & $0.630(0.398-0.997)$ & 0.049 & $0.599(0.375-0.957)$ & 0.032 \\
\hline$>11$ & $0.527(0.329-1.845)$ & 0.008 & $0.434(0.269-0.701)$ & 0.001 \\
\hline
\end{tabular}

Surgeons Oncology Group (ACOSOG) Z0030 trial which had a superb quality of N2 LN examination [21]. There is no apparent difference in the median number of N2 LNs examined between this study and the ACOSOG Z0030 trial. As the number of N2 LNs examined increases, the survival advantage decreases when the quality of N2 LN examination increases to a high level. The number of N2 LNs examined lost statistical significance in the Cox regression model. However, this result cannot deny the vital role of N2 LN examination in node staging. Both N1 and N2 LN examinations are important for accurate node staging.

Some researchers have focused on the importance of the number of N1 LNs examined. Saynak et al. reported that T1N0 patients with inadequate N1 LNs examined had similar local recurrence-free survival compared with T1N1 patients [22]. The ACOSOG Z0030 trial also found a tendency that the greater the number of intrapulmonary LNs examined, the better the patient survival outcomes [23]. Varlotto et al. demonstrated that a minimum of 11 to 16 LNs should be examined when examining only N1 lymph nodes [24]. Similar to the finding of the above study, patients with more than 11 N1 LNs examined had the lowest HR values in the multivariate analyses of OS and DFS, signifying that at least $12 \mathrm{~N} 1$ LNs should be examined to achieve optimal OS and DFS. However, it is difficult to accomplish this goal in clinical practice. Only $26.2 \%$ of patients accepted the examination of more than $11 \mathrm{~N} 1 \mathrm{LNs}$ in this study. On the one hand, patients with $6-8 \mathrm{~N} 1 \mathrm{LNs}$ examined had the second lowest $H R$ values in the multivariate analysis of OS, and patients with more than $5 \mathrm{~N} 1 \mathrm{LNs}$ examined had better OS and DFS in landmark 5-year follow-up. The survival analyses showed examining at least $6 \mathrm{~N} 1$ 
Table 3 Univariate and multivariate analysis of DFS

\begin{tabular}{|c|c|c|c|c|}
\hline \multirow[t]{2}{*}{ Factors } & \multicolumn{2}{|l|}{ Univariate analysis } & \multicolumn{2}{|c|}{ Multivariate analysis } \\
\hline & HR (95\% Cl) & $P$ value & HR (95\% Cl) & $P$ value \\
\hline Gender & $0.570(0.458-0.709)$ & $<0.001$ & $0.665(0.496-0.892)$ & 0.006 \\
\hline Age (year) & $1.018(1.007-1.029)$ & 0.002 & $1.012(1.001-1.023)$ & 0.039 \\
\hline Tumor size $(\mathrm{cm})$ & $1.402(1.278-1.538)$ & $<0.001$ & $1.232(1.089-1.394)$ & 0.001 \\
\hline Smoking history & $1.537(1.258-1.877)$ & $<0.001$ & $1.026(0.780-1.348)$ & 0.856 \\
\hline $8^{\text {th }}$ TNM stage & $1.938(1.570-2.393)$ & $<0.001$ & $1.386(0.997-1.928)$ & 0.052 \\
\hline Visceral pleural invasion & $1.333(1.088-1.631)$ & 0.005 & $1.053(0.799-1.373)$ & 0.709 \\
\hline \multicolumn{5}{|l|}{ Histology } \\
\hline Squamous cell carcinoma & Ref & & Ref & \\
\hline Adenocarcinoma & $0.782(0.611-0.999)$ & 0.049 & $1.222(0.926-1.614)$ & 0.157 \\
\hline Others & $0.946(0.666-1.433)$ & 0.905 & $1.179(0.789-1.762)$ & 0.422 \\
\hline Differentiation degree & $1.559(1.323-1.838)$ & $<0.001$ & $1.338(1.124-1.592)$ & 0.001 \\
\hline Vascular invasion & $1.982(1.378-2.852)$ & $<0.001$ & $1.474(1.006-2.160)$ & 0.047 \\
\hline \multicolumn{5}{|l|}{ Number of N2 LNs examined } \\
\hline $0-2$ & Ref & & & \\
\hline $3-5$ & $0.627(0.391-1.005)$ & 0.052 & $0.730(0.451-1.180)$ & 0.199 \\
\hline $6-8$ & $0.841(0.545-1.297)$ & 0.433 & $0.916(0.590-1.423)$ & 0.696 \\
\hline $9-11$ & $0.737(0.470-1.156)$ & 0.183 & $0.826(0.522-1.307)$ & 0.413 \\
\hline $12-14$ & $0.730(0.463-1.151)$ & 0.175 & $0.869(0.545-1.385)$ & 0.554 \\
\hline$>14$ & $0.759(0.505-1.142)$ & 0.186 & $0.665(0.555-1.285)$ & 0.431 \\
\hline Adjuvant chemotherapy & $1.127(0.858-1.481)$ & 0.500 & & \\
\hline Thoracotomy or VATS & $0.933(0.763-1.141)$ & 0.304 & & \\
\hline \multicolumn{5}{|c|}{ Number of $\mathrm{N} 1$ stations examined } \\
\hline $0-2$ & Ref & & Ref & \\
\hline $3-5$ & $0.654(0.464-0.922)$ & 0.015 & $0.640(0.452-0.906)$ & 0.012 \\
\hline $6-8$ & $0.680(0.486-0.949)$ & 0.024 & $0.658(0.469-0.924)$ & 0.016 \\
\hline $9-11$ & $0.595(0.418-0.847)$ & 0.004 & $0.585(0.407-0.839)$ & 0.004 \\
\hline$>11$ & $0.627(0.445-0.884)$ & 0.008 & $0.557(0.391-0.793)$ & 0.001 \\
\hline
\end{tabular}

LNs could bring survival advantages. On the other hand, the median number of $\mathrm{N} 1$ LNs examined in this study was 8 , which means that more than half of the patients did not have at least $9 \mathrm{~N} 1 \mathrm{LNs}$ examined. As a comparison, the median number of $\mathrm{N} 1 \mathrm{LNs}$ examined was 5 in the ACOSOG Z0030 trial and 5 in Saynak et al.'s study. It is not easy to examine at least $9 \mathrm{~N} 1 \mathrm{LNs}$ for each patient. The clinical decision should be feasible, and at least $6 \mathrm{~N} 1 \mathrm{LNs}$ examined is a realistic goal in clinical practice. Therefore, we recommend at least 6 N1 LNs examined in surgical and pathological management.

However, the examination of N1 LNs has not received enough attention. One of the phenomena was that the quality of LN examination exhibits noteworthy variability during surgical and pathological management $[25,26]$. Another phenomenon is that incomplete intrapulmonary LNs were retrieved in pathological examination. One previous study revealed that a median of six additional LNs was discovered after rechecking remnant lung specimens, and the median number of N1 LNs examined was only 3 in the community-based Memphis Metropolitan Area Quality of Surgical Resection cohort [27]. Although N2 LN examinations were of superb quality, the median number of N1 LNs examined was 5 in the ACOSOG Z0030 trial [21]. In this study, the median number of resected N1 LNs was eight. The pattern of LN examination in which N1 LNs were dissected by surgeons and reconfirmed by pathologists contributed to this result.

In addition to insufficient attention to N1 LN examination possibly affecting the number of N1 LNs examined, the surgical approach may also affect the number of N1 LNs examined. Subramanian et al. reviewed 1687 patients with stage IA NSCLC from the National Cancer Database, and included 1354 patients who underwent lobectomy and 333 patients who underwent sublobar resections. They found that sublobar resection had 

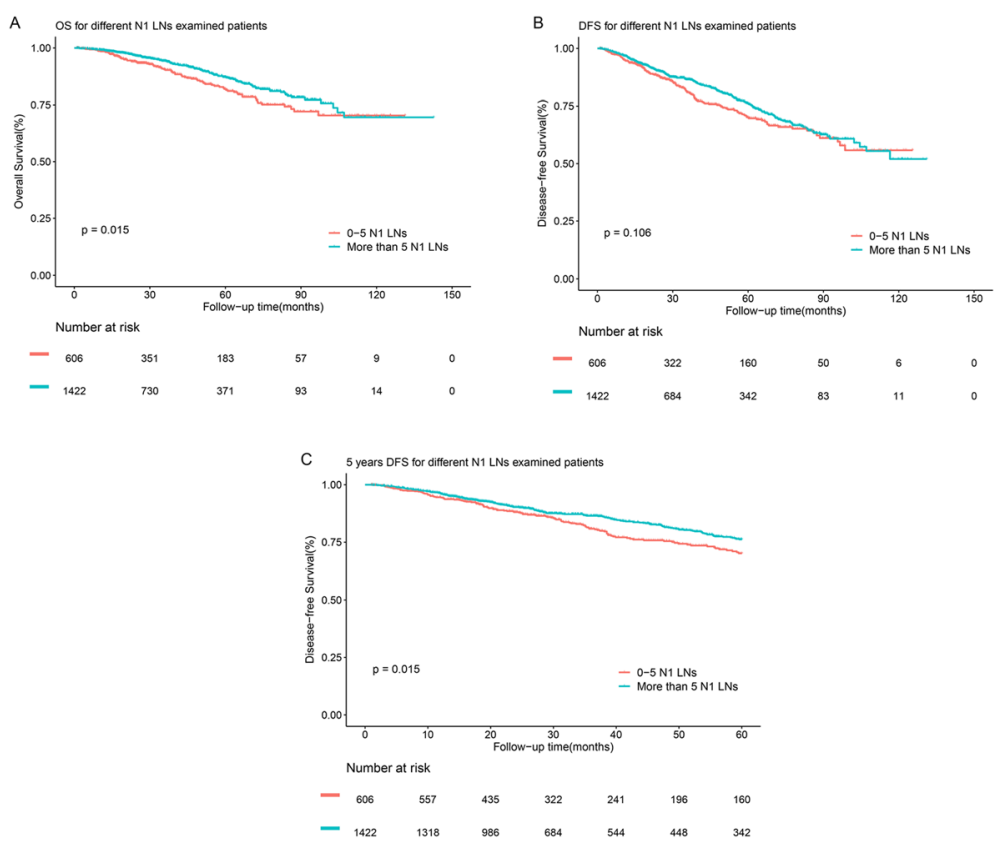

Fig. 3 a OS for patients with 0-5 and more than 5 N1 LNs examined patients. $\mathbf{b}$ DFS for patients with 0-5 and more than 5 N1 N1 LNs examined patients. c Five-year DFS for patients with $0-5$ and more than 5 N1 LNs examined patients

inadequate LNs examined and was associated with a $39 \%$ increased risk of recurrence. The majority of patients were treated with sublobar resection [28]. For both sublobar resection and lobectomy, the procedure of mediastinal LN dissection does not have apparent differences. However, sublobar resection, especially wedge resection, might lose some N1 LNs, which is associated with poor outcomes. In addition, when we dissected intrapulmonary LNs, we found a phenomenon in which patients whose primary tumor was near a segmental bronchus were prone to segmental LN metastases. Therefore, we suggest that patients whose primary tumor is near a segmental bronchus need a careful intrapulmonary LN dissection. Furthermore, intrapulmonary LNs are dissected extracorporeally, if 6 lymph nodes were not dissected in the first operation, it is safe to dissect the lung specimens again to take an LN sample for accurate staging.

There are some limitations to this study. First, this was a single-center retrospective study and associated biases may have been inevitable, and external validation was not performed to validate the findings. Second, this study lacks incidence of local LN failure which makes "stage migration" more convincing. Although intrapulmonary node was removed with lobe, local LN failure will still be associated with unsatisfied hilar LN dissection. In addition, the data of this study did not find a survival advantage from the increase in the number of N2 LNs examined and cannot answer how many N2 LNs should be examined in surgical and pathological management. Therefore, further validation from multicenter database is needed, and, the findings from this study should be cautiously interpreted.

\section{Conclusions}

Increasing the number of N1 LNs examined might improve the long-term survival of T1-2N0 NSCLC patients. The data of this study indicate that at least $6 \mathrm{~N} 1$ nodes examined is an essential part in surgical and pathological management but cannot prove this. This finding should be confirmed in a large, prospective randomized clinical study.

\section{Abbreviations}

NSCLC: Non-small cell lung cancer; LDCT: Low-dose computed tomography; NCCN: National Comprehensive Cancer Network; LN: Lymph node; OS: Overall survival; DFS: Disease-free survival; ACOSOG: American College of Surgeons Oncology Group

\section{Acknowledgements}

Not applicable

\section{Authors' contributions}

JYW and WYZ designed the study. FFD, YZZ, and WYZ drafted the manuscript. QHY, SQD, TC, and JLC collected and interpreted the data. WYZ carried out the statistical analysis. FFD and YZZ critically revised the manuscript. All authors read and approved the final manuscript.

\section{Funding}

This work was supported by the Natural Science Foundation of Guangdong Province of China (grant numbers 2019A1515011601, 2019A1515010298)

\section{Availability of data and materials}

The key raw data have been deposited into the Research Data Deposit (http://www.researchdata.org.cn), with the approval number of

RDDA2020001355, and the datasets used in this study are publicly available. 


\section{Ethics approval and consent to participate}

This study was approved by the Institutional Review Board of Sun Yat-sen University Cancer Center.

\section{Consent for publication}

All patients enrolled in the study signed the consent for publication

\section{Competing interests}

The authors declare that they have no competing interests

\section{Author details}

'Department of Thoracic Surgery, State Key Laboratory of Oncology in South China, Collaborative Innovation Center for Cancer Medicine, Sun Yat-sen University Cancer Center, Guangzhou, Guangdong, People's Republic of China. ${ }^{2}$ VIP Region, State Key Laboratory of Oncology in South China, Collaborative Innovation Center for Cancer Medicine, Sun Yat-sen University Cancer Center, Guangzhou, Guangdong, People's Republic of China. ${ }^{3}$ Department of Thoracic Surgery, Sun Yat-sen University Sixth Affiliated Hospital, Guangzhou, Guangdong, People's Republic of China. ${ }^{4}$ Department of Laboratory Medicine, State Key Laboratory of Oncology in South China, Collaborative Innovation Center for Cancer Medicine, Sun Yat-sen University Cancer Center, Guangzhou, Guangdong, People's Republic of China. ${ }^{5}$ Department of Thoracic Surgery, The People's Hospital of Chao Zhou, Chao Zhou, Guangdong, People's Republic of China. ${ }^{6}$ Department of Thoracic Surgery, The Second People's Hospital of Shan Tou, Shan Tou, Guangdong, People's Republic of China.

Received: 20 April 2020 Accepted: 10 September 2020

Published online: 30 September 2020

\section{References}

1. Feng RM, Zong YN, Cao SM, Xu RH. Current cancer situation in China: good or bad news from the 2018 global cancer statistics? Cancer Commun (Lond). 2019;39(1):22

2. Howington JA, Blum MG, Chang AC, Balekian AA, Murthy SC. Treatment of stage I and II non-small cell lung cancer: diagnosis and management of lung cancer, 3rd ed: American College of Chest Physicians evidence-based clinical practice guidelines. Chest. 2013;143(5 Suppl):e278S-313S.

3. Jin K, Zhang K, Zhou F, Dai J, Zhang P, Jiang G. Selection of candidates for surgery as local therapy among early-stage small cell lung cancer patients: a population-based analysis. Cancer Commun (Lond). 2018;38(1):5.

4. Eberhardt WE, Mitchell A, Crowley J, Kondo H, Kim YT, Turrisi A III, et al. The IASLC lung cancer staging project: proposals for revision of the TNM stage groupings in the forthcoming (eighth) edition of the TNM classification for lung cancer. J Thorac Oncol. 2016;11(1):39-51.

5. Kelsey CR, Marks LB, Hollis D, Hubbs JL, Ready NE, D'Amico TA, et al. Local recurrence after surgery for early stage lung cancer: an 11-year experience with 975 patients. Cancer. 2009:115(22):5218-27.

6. Lardinois D, Suter H, Hakki H, Rousson V, Betticher D, Ris HB. Morbidity, survival, and site of recurrence after mediastinal lymph-node dissection versus systematic sampling after complete resection for non-small cell lung cancer. Ann Thorac Surg. 2005;80(1):268-74 discussion 74-5.

7. Massard G, Ducrocq X, Kochetkova EA, Porhanov VA, Riquet M. Sampling or node dissection for intraoperative staging of lung cancer: a multicentric cross-sectional study. Eur J Cardiothorac Surg. 2006;30(1):164-7.

8. Dai Y, Su X, Long H, Lin P, Fu J, Zhang L, et al. Survival analysis of 220 patients with completely resected stage-II non-small cell lung cancer. Chinese J Cancer. 2010;29(5):538-44.

9. Doddoli C, Aragon A, Barlesi F, Chetaille B, Robitail S, Giudicelli R, et al. Does the extent of lymph node dissection influence outcome in patients with stage I non-small-cell lung cancer? Eur J Cardiothorac Surg. 2005;27(4):680-5.

10. Liang W, He J, Shen Y, Shen J, He Q, Zhang J, et al. Impact of Examined Lymph Node Count on Precise Staging and Long-Term Survival of Resected Non-Small-Cell Lung Cancer: A Population Study of the US SEER Database and a Chinese Multi-Institutional Registry. J Clin Oncol. 2017;35(11):1162-70.

11. Whitson BA, Groth SS, Maddaus MA. Surgical assessment and intraoperative management of mediastinal lymph nodes in non-small cell lung cancer. Ann Thorac Surg. 2007:84(3):1059-65.

12. Ishiguro F, Matsuo K, Fukui T, Mori S, Hatooka S, Mitsudomi T. Effect of selective lymph node dissection based on patterns of lobe-specific lymph node metastases on patient outcome in patients with resectable non-small cell lung cancer: a large-scale retrospective cohort study applying a propensity score. J Thorac Cardiovasc Surg. 2010;139(4):1001-6.

13. Jiang $W$, Chen $X, X i J$, Wang Q. Selective mediastinal lymphadenectomy without intraoperative frozen section examinations for clinical stage I nonsmall-cell lung cancer: retrospective study of 403 cases. World J Surg. 2013; 37(2):392-7.

14. Zhang Z, Miao J, Chen Q, Fu Y, Li H, Hu B. Assessment of non-lobe-specific lymph node metastasis in clinical stage IA non-small cell lung cancer. Thorac Cancer. 2019;10(7):1597-604.

15. Veeramachaneni NK, Battafarano RJ, Meyers BF, Zoole JB, Patterson GA. Risk factors for occult nodal metastasis in clinical T1N0 lung cancer: a negative impact on survival. Eur J Cardiothorac Surg. 2008;33(3):466-9.

16. May M, Herrmann E, Bolenz C, Brookman-May S, Tiemann A, Moritz R, et al. Association between the number of dissected lymph nodes during pelvic lymphadenectomy and cancer-specific survival in patients with lymph node-negative urothelial carcinoma of the bladder undergoing radical cystectomy. Ann Surg Oncol. 2011;18(7):2018-25.

17. Samayoa AX, Pezzi TA, Pezzi CM, Gay EG, Asai M, Kulkarni N, et al. Rationale for a minimum number of lymph nodes removed with non-small cell lung cancer resection: correlating the number of nodes removed with survival in 98,970 patients. Ann Surg Oncol. 2016;23:1005-11.

18. Galon J, Costes A, Sanchez-Cabo F, Kirilovsky A, Mlecnik B, LagorcePagès $C$, et al. Type, density, and location of immune cells within human colorectal tumors predict clinical outcome. Science (New York, NY). 2006;313(5795):1960-4.

19. Galon J, Fridman WH, Pagès $F$. The adaptive immunologic microenvironment in colorectal cancer: a novel perspective. Cancer Res. 2007:67(5):1883-6.

20. Ou SH, Zell JA. Prognostic significance of the number of lymph nodes removed at lobectomy in stage IA non-small cell lung cancer. J Thorac Oncol. 2008;3(8):880-6.

21. Darling GE, Allen MS, Decker PA, Ballman K, Malthaner RA, Inculet RI, et al. Number of lymph nodes harvested from a mediastinal lymphadenectomy: results of the randomized, prospective American College of Surgeons oncology group Z0030 trial. Chest. 2011;139(5):1124-9.

22. Saynak M, Hubbs J, Nam J, Marks LB, Feins RH, Haithcock B, et al. Variability in defining T1NO non-small cell lung cancer impacts locoregional failure and survival. Ann Thorac Surg. 2010;90(5):1645-9 discussion 9-50.

23. Osarogiagbon RU, Decker PA, Ballman K, Wigle D, Allen MS, Darling GE. Survival implications of variation in the thoroughness of pathologic lymph node examination in American College of Surgeons oncology group Z0030 (Alliance). Ann Thorac Surg. 2016;102(2):363-9.

24. Varlotto JM, Abram R, Margaret N, Flickinger JC, Decamp MM. Extent of lymphadenectomy and outcome for patients with stage I nonsmall cell lung cancer. Cancer. 2010;115(4):851-8.

25. Little AG, Rusch WW, Bonner JA, Gaspar LE, Green MR, Webb WR, et al. Patterns of surgical care of lung cancer patients. Ann Thorac Surg. 2005; 80(6):2051-6 discussion 6

26. Farjah F, Flum DR, Varghese TK Jr, Symons RG, Wood DE. Surgeon specialty and long-term survival after pulmonary resection for lung cancer. Ann Thorac Surg. 2009:87(4):995-1006.

27. Ramirez RA, Wang CG, Miller LE, Adair CA, Berry A, Yu X, et al. Incomplete intrapulmonary lymph node retrieval after routine pathologic examination of resected lung cancer. J Clin Oncol. 2012;30(23):2823-8.

28. Subramanian M, McMurry T, Meyers BF, et al. Long-term results for clinical stage IA lung cancer: comparing lobectomy and sublobar resection. Ann Thorac Surg. 2018:106(2):375-81.

\section{Publisher's Note}

Springer Nature remains neutral with regard to jurisdictional claims in published maps and institutional affiliations. 